\title{
PENGEMBANGAN WEBSITE "SUNTING PINTAR" SEBAGAI INOVASI PEMBELAJARAN PENYUNTINGAN BAGI MAHASISWA BERBASIS LIFE SKILL DAN ENTREPRENEURSHIP
}

\author{
Ariva Luciandika ${ }^{1}$, Kusubakti Andajani ${ }^{2}$, Dewi Ariani ${ }^{3}$, Manavavee Mamah ${ }^{4}$ \\ ${ }^{1,2,3}$ Pendidikan Bahasa, Sastra Indonesia, dan Daerah, Universitas Negeri Malang \\ Jalan Semarang Nomor 5, Sumbersari, Lowokwaru, Malang, Jawa Timur \\ ${ }^{4}$ Sub-Program Melayu Language, Yala Rajabhat University \\ 133 Thetsaban 3 Road, Tambol Sateng, Amphoe Mueang, Yala Province, Thailand \\ 1e-mail: ariva.luciandika.fs@um.ac.id

\begin{tabular}{|c|c|c|c|c|c|}
\hline $\begin{array}{c}\text { Submitted } \\
2021-08-16\end{array}$ & $\begin{array}{c}\text { Accepted } \\
2021-11-24\end{array}$ & $\begin{array}{l}\text { Published } \\
\text { 2021-12-07 }\end{array}$ & open $\partial_{\text {Access }}$ & (c) (7) () & antinta 3 \\
\hline
\end{tabular}

\section{Abstrak}

Tujuan penelitian adalah mengembangkan media pembelajaran penyuntingan melalui aplikasi "Sunting Pintar". Aplikasi tersebut merupakan laman interaktif yang digunakan dosen dan mahasiswa dalam pembelajaran penyuntingan. Laman terdiri atas tiga portal, yaitu admin (dosen), editor (mahasiswa), dan pengguna (masyarakat). Metode penelitian menggunakan constructivist instructional design yang terdiri atas 4 tahap, yaitu define, design, development, dan dissemination. Produk divalidasi oleh ahli bahasa dan praktisi untuk mengukur kelayakan dan kemudian diujicobakan pada mahasiswa. Responden uji coba sebanyak 30 mahasiswa yang mengikuti mata kuliah Penyuntingan dan 10 mahasiswa Jurusan Bahasa Melayu, Faculty of Humanities and Social Sciences, Yala Rajabhat University, Thailand. Teknik analisis data yang digunakan adalah deskriptif kualitatif. Berdasarkan hasil validasi dan uji coba, maka disimpulkan bahwa produk berada pada kategori layak untuk diimplementasikan dengan memperhatikan saran dari validator terkait penambahan konten materi penyuntingan dan ilustrasi gambar dalam aplikasi.

Kata Kunci: entrepreneurship; kecakapan hidup; website Sunting Pintar.

\begin{abstract}
The purpose of this research was to develop editing learning media through the "Sunting Pintar" application. The application was an interactive page that was used by lecturers and students in learning editing. The page consists of three portals, namely admin (lecturer), editor (student), and user (community). This research method used constructivist instructional design which consists of 4 stages, namely define, design, development, and dissemination. The product was validated by linguists and practitioners to measure feasibility and then piloted on students. The trial respondents were 30 students who took the Editing course and 10 students of the Malay Language Department, Faculty of Humanities and Social Sciences, Yala Rajabhat University, Thailand. The data analysis technique used descriptive qualitative. Based on the results of the validation and testing, it was concluded that the product was in a feasible category to be implemented by taking into account the suggestions from the validator regarding the addition of editing material content and image illustrations in the application.
\end{abstract}

Keywords: entrepreneurship; life skill; Sunting Pintar website. 


\section{PENDAHULUAN}

Pembelajaran di Indonesia telah mengalami banyak perkembangan, baik di tingkat sekolah maupun perguruan tinggi. Seiring perkembangan ilmu pengetahuan dan teknologi, lulusan tidak hanya dituntut menguasai bidang ilmu tertentu, tetapi juga mengaplikasikannya. Hal tersebut sesuai dengan Peraturan Pemerintah Nomor 4 Tahun 2014 tentang Penyelenggaraan Pendidikan Tinggi dan Pengelolaan Pendidikan Tinggi Pasal 1 ayat 7 yang menyatakan bahwa universitas dapat menyelenggarakan pendidikan akademik dan pendidikan vokasi dalam berbagai rumpun ilmu pengetahuan dan teknologi. Oleh karenanya, perguruan tinggi perlu menyelenggarakan pendidikan vokasi agar lulusan memiliki kualifikasi dan kecakapan hidup (life skill).

Proses pembelajaran di perguruan tinggi yang memberikan life skill akan berdampak pada penguasaan ilmu tidak hanya pada ranah teoretis. Prinsip pendidikan life skill, yaitu: (1) Tidak mengubah sistem pendidikan yang berlaku; (2) Mengembangkan kurikukum; (3) Etika sosio-religius dalam proses belajar; (4) Berdasarkan empat pilar pembelajaran, dan (5) Mengarahkan untuk mendapat hidup yang berkualitas (Widiasworo, 2017). Pembelajaran di perguruan tinggi perlu diintegrasikan ke prinsip-prinsip life skill. Integrasi life skill dalam pembelajaran akan optimal jika didukung penerapan konsep entrepreneurship. Entrepreneurship dapat diartikan seorang yang memilih bidang usaha yang cocok dengan kemampuan dan minatnya, mempelajari, mengamati, mengumpulkan informasi, dan bergerak untuk membangun usaha (Margahana \& Triyanto, 2019).

Pembelajaran berbasis entrepreneurship di perguruan tinggi berarti menanamkan kepribadian wirausaha sehingga mahasiswa dapat menciptakan peluang usaha di luar bidang keahlian. Contohnya pada Program Studi Pendidikan Bahasa dan Sastra Indonesia. Fokus kompetensi yang diajarkan pada mahasiswa berkaitan dengan prinsip-prinsip pembelajaran. Terdapat kompetensi lain yang bisa dieksplorasi oleh lulusan, misalnya penyuntingan. Penyuntingan bermakna proses, cara, perbuatan menyunting atau sunting-menyunting (KBBI, 2021). 
Setiap penulisan naskah jenis apapun, memerlukan penyuntingan. Hal tersebut dapat menjadi peluang usaha untuk mahasiswa yang memiliki kompetensi di bidang penyuntingan. Tidak semua mahasiswa memiliki kemampuan penyuntingan yang baik karena penyunting tidak hanya menghadapi persoalan teknis dalam memperbaiki naskah yang berkaitan dengan kaidah kebahasaan (Supriyana, 2018).

Masalah yang terjadi dalam pembelajaran penyuntingan yaitu hanya sebatas paparan teori dan praktik terbatas dalam kelas. Sebelum penelitian dimulai, dilakukan studi pendahuluan berupa wawancara dengan dosen pengampu mata kuliah Penyuntingan. Menurut hasil wawancara, dosen hanya memberikan teori, meminta mahasiswa mempresentasikan hasil diskusi kelompok, dan melakukan praktik penyuntingan dalam kelas. Naskah yang disunting telah disiapkan sebelumnya oleh dosen. Pembelajaran tersebut tidak memfasilitasi mahasiswa untuk secara langsung menjawab kebutuhan masyarakat pengguna. Oleh karenanya, dibutuhkan media pembelajaran yang memfasilitasi mahasiswa untuk menerapkan teori penyuntingan secara langsung dalam masyarakat. Urgensi penelitian adalah mengembangkan media pembelajaran berbasis digital yang dapat dimanfaatkan mahasiswa untuk mempelajari materi penyuntingan yang berorientasi pada penanaman konsep life skill dan entrepreneurship sejak dini.

Penelitian pengembangan sudah pernah dilakukan dengan melibatkan teknologi digital dalam pembelajaran (Nurhidayat et al., 2020; Setiawan et al., 2019; Miller, 2018; Lamrani et al., 2018). Hasil-hasil penelitian tersebut berfokus pada perancangan media inovatif untuk pembelajaran secara mandiri. Pengajar tidak dapat terlibat secara langsung untuk mengontrol penggunaannya. Perbedaan penelitian yang dilakukan dengan penelitian sebelumnya adalah inovasi berupa keterlibatan dosen secara langsung. Laman terdiri atas portal untuk dosen, mahasiswa, dan pengguna. Ketiganya saling terhubung satu sama lain, sehingga dosen bisa mengontrol hasil kerja mahasiswa. Laman menawarkan jasa sunting artikel, skripsi, tesis, disertasi, atau naskah lain untuk pengguna yang telah melakukan pendaftaran. Oleh karenanya, laman tidak sekadar menjadi media praktik penyuntingan, namun juga memberikan keuntungan finansial bagi 
Edukasi: Jurnal Pendidikan, Volume 19 Nomor 2 Tahun 2021

Pengembangan Website "Sunting Pintar" sebagai Inovasi.......

Ariva Luciandika, Kusubakti Andajani, Dewi Ariani, Manavavee Mamah

Halaman 260-274

mahasiswa yang menjadi editor, sehingga tujuan penelitian adalah mengembangkan aplikasi berupa laman "Sunting Pintar" yang layak dari komponen isi, sistematika, bahasa, dan tampilan.

\section{METODE}

Metode penelitian menggunakan penelitian dan pengembangan. Desain yang digunakan adalah Constructivist Instructional Design (CID), yaitu suatu model pengembangan pembelajaran dengan pendekatan konstruktivistik berpola kerja R2D2. Esensi CID yaitu mengonstruksi langkah-langkah tertentu untuk memecahkan masalah. Langkah-langkah CID terdiri dari define, design, development, dan dissemination. Fokus penelitian yaitu menemukan masalah, merancang desain produk, melakukan uji ahli dan uji coba, serta desiminasi produk. Tahap define dilakukan dengan terlebih dulu mengobservasi Rencana Perkuliahan Semester (RPS), wawancara dengan dosen pengampu mata kuliah, mengamati kondisi mahasiswa, dan prospek calon lulusan di masa mendatang. Selanjutnya dilakukan identifikasi potensi hal-hal yang perlu dikembangkan, terutama berkaitan dengan metode pembelajaran penyuntingan.

Hal yang dilakukan dalam tahap design adalah perancangan aplikasi dengan memperhatikan fokus kajian yang telah ditetapkan. Tahap development diwujudkan dalam kegiatan uji validasi untuk mengukur kelayakan produk dari komponen isi, sistematika, kebahasaan, dan tampilan. Pengukuran kelayakan produk telah disiapkan instrumen yang akan diisi oleh validator. Validator kelayakan produk sebanyak dua orang, yaitu ahli pembelajaran bahasa Indonesia dan praktisi teknologi informasi. Parameter kelayakan diklasifikasikan menjadi empat skala skor, yaitu 4 (sangat baik/sangat sesuai/sangat layak/sangat jelas), 3 (baik/sesuai/layak/jelas), 2 (kurang baik/kurang sesuai/kurang layak/ kurang jelas), dan 1 (tidak baik/tidak sesuai/tidak layak/tidak jelas). Selain skala skor 1-4, kelayakan juga diklasifikasikan dalam bentuk persentase berdasarkan kriteria pada Tabel 1 (Arikunto, 2011). 


\section{Tabel 1 Kriteria Kelayakan Produk}

\begin{tabular}{cc}
\hline Persentase Skor & Kategori Kelayakan \\
\hline $0 \%-40 \%$ & Tidak layak \\
$41 \%-60 \%$ & Kurang layak \\
$61 \%-80 \%$ & Layak \\
$81 \%-100 \%$ & Sangat layak \\
\hline
\end{tabular}

Setelah dilakukan uji validasi, produk diujicobakan pada mahasiswa. Uji coba dilakukan dengan meminta mahasiswa mengoperasikan laman suntingpintar.id, kemudian memberikan penilaian terkait kelayakan produk dari komponen isi, sistematika, bahasa, dan tampilan berdasarkan instrumen yang sudah disiapkan. Responden uji coba sebanyak 30 mahasiswa Jurusan Sastra Indonesia, Fakultas Sastra, Universitas Negeri Malang dari keseluruhan populasi 64 mahasiswa yang mengikuti kelas Penyuntingan dan 10 mahasiswa Jurusan Bahasa Melayu, Faculty of Humanities and Social Sciences, Yala Rajabhat University, Thailand yang dipilih secara acak. Tahap dissemination yaitu publikasi artikel ilmiah pada jurnal nasional terakreditasi.

\section{HASIL DAN PEMBAHASAN}

Peneliti menemukan urgensi masalah yang terkait dengan pembelajaran penyuntingan pada tahap define. Setelah dilakukan observasi terhadap RPS dan wawancara dengan dosen pengampu, diketahui kondisi mahasiswa dan prospek calon lulusan di masa mendatang. Calon lulusan Jurusan Sastra Indonesia tidak hanya dapat memperoleh pekerjaan di bidang pendidikan, namun dapat mengembangkan life skill di bidang lain. Berdasarkan identifikasi potensi, yang perlu dikembangkan adalah media pembelajaran penyuntingan.

Produk penelitian yang dihasilkan pada tahap design berupa laman media penyuntingan dengan nama "Sunting Pintar". Laman dikembangkan dengan melibatkan programmer. Laman terdiri atas tiga portal, yaitu admin, editor, dan pengguna. Admin adalah dosen, editor adalah mahasiswa, dan pengguna adalah masyarakat umum yang membutuhkan jasa penyuntingan. Ketiga portal tersebut saling terhubung dan berkaitan. Dosen mengonfirmasi pendaftaran pengguna, menerima naskah dari pengguna, mengentri nama mahasiswa yang menjadi 
Edukasi: Jurnal Pendidikan, Volume 19 Nomor 2 Tahun 2021

Pengembangan Website "Sunting Pintar" sebagai Inovasi......

Ariva Luciandika, Kusubakti Andajani, Dewi Ariani, Manavavee Mamah

Halaman 260-274

editor, memberi tugas, dan mengomentari hasil editing. Mahasiswa melakukan penyuntingan setelah mendapat tugas dari dosen. Mahasiswa juga dapat mengunduh materi penyuntingan, KBBI, dan Pedoman Penulisan Karya Ilmiah.

Produk bisa diakses melalui komputer, laptop, atau ponsel pengguna. Pengguna harus memasukkan data pribadi dan memilih jenis naskah yang akan disunting. Data tersebut akan masuk ke portal dosen sebagai admin. Admin akan menentukan estimasi waktu pengerjaan dan biaya. Setelah pengguna menyelesaikan pembayaran, admin akan memverifikasi dan memberikan tugas penyuntingan pada editor. Berikut disajikan tampilan laman "Sunting Pintar".

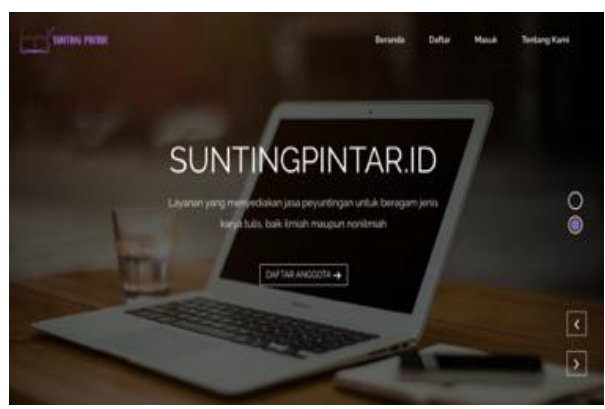

(a)

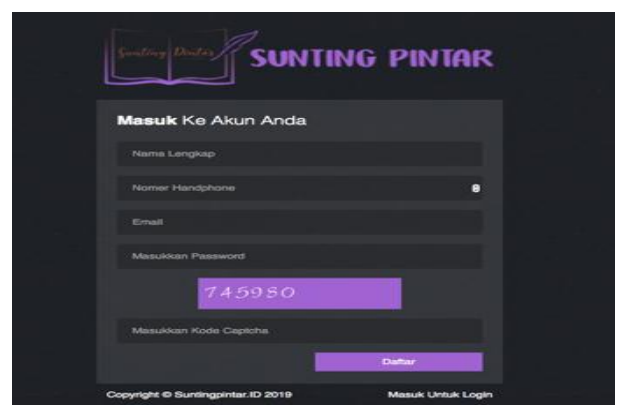

(b)

\section{Gambar 1 (a) Tampilan Awal Laman (b) Tampilan Form Pendaftaran}

Gambar 1(a) merupakan tampilan awal laman yang berisi deskripsi singkat tentang "Sunting Pintar". Bagian tersebut juga terdapat penjelasan tentang tim penyunting dan fasilitas yang disediakan untuk pengguna. Gambar 1(b) merupakan tampilan pendaftaran. Pengguna harus melakukan registrasi dengan menuliskan nama, telepon, surel, instansi, dan jenis naskah yang akan disunting.

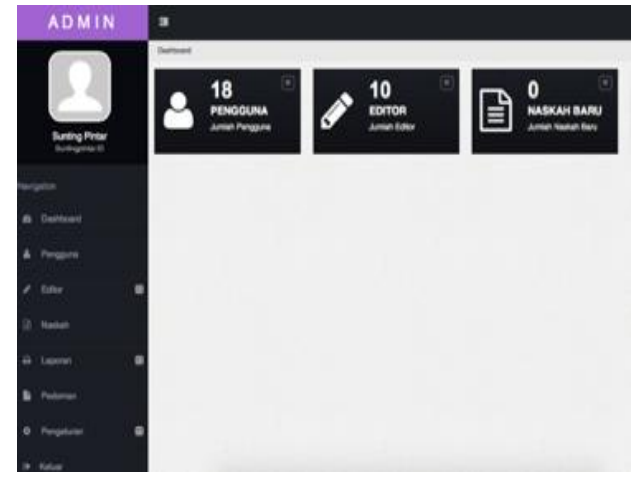

(a)

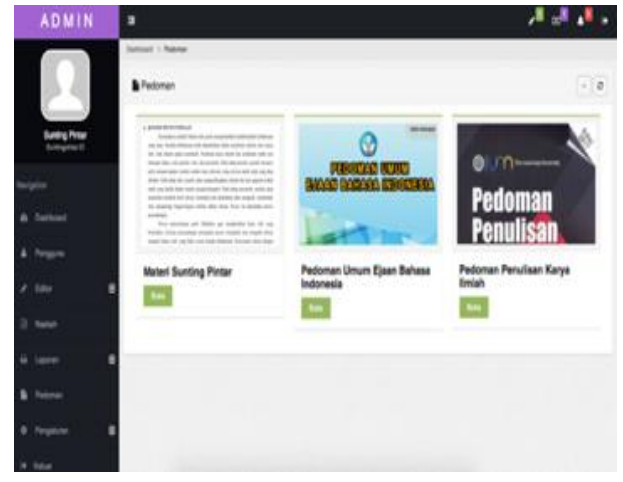

(b)

Gambar 2 (a) Tampilan di Portal Admin Bagian Data Pengguna

(b) Tampilan di Portal Admin Bagian Sajian Materi 
Gambar 2(a) merupakan tampilan di portal admin. Admin memverifikasi semua pengguna yang mendaftar. Data jumlah pengguna, informasi pembayaran, dan status naskah akan tampak di portal admin. Gambar 2(b) merupakan tampilan di bagian sajian materi. Admin dapat mengunggah materi-materi untuk editor.

Data penelitian diperoleh dari hasil pengisian instrumen saat uji ahli dan uji coba pada tahap development. Hasil uji validasi dianalisis dan dilakukan revisi produk sesuai saran dari validator. Jika rerata hasil uji validasi lebih dari sama dengan $61 \%$, produk dinyatakan layak dan dapat diimplementasikan. Kode X adalah jawaban uji ahli dalam satu item, Xi adalah nilai maksimal dalam satu item, HU adalah persentase hasil uji, TL adalah tindak lanjut, I adalah implementasi, dan $\mathrm{R}$ adalah revisi. Berdasarkan Tabel 2, diperoleh rerata skor 87\% pada komponen isi, sehingga produk dikategorikan sangat layak dan siap diimplementasikan.

Tabel 2 Data Hasil Uji Ahli Pembelajaran Bahasa Indonesia Komponen Isi Aplikasi

\begin{tabular}{llcccc}
\hline \multicolumn{1}{c}{ Indikator } & \multicolumn{2}{c}{ Butir Penilaian } & \multicolumn{4}{c}{ Penilaian } \\
\cline { 3 - 6 } \multicolumn{1}{c}{ Penilaian } & \multicolumn{1}{c}{ X } & Xi & HU & TL \\
\hline Kesesuaian isi & Kelengkapan isi & 4 & 4 & $95 \%$ & I \\
dengan capaian & Kesesuaian isi dengan tujuan & 4 & 4 & $90 \%$ & I \\
& Kesesuaian dengan tujuan belajar & 3 & 4 & $80 \%$ & I \\
Keakuratan & Kelengkapan isi materi & 4 & 4 & $90 \%$ & I \\
materi & Kedalaman isi materi & 3 & 4 & $80 \%$ & I \\
Pendukung & Keterkaitan isi dengan materi & 4 & 4 & $95 \%$ & I \\
materi & Komunikasi mahasiswa-dosen & 3 & 4 & $75 \%$ & I \\
pembelajaran & Mendorong mahasiswa aktif & 4 & 4 & $80 \%$ & I \\
Kemutakhiran & Kesesuaian dengan teknologi & 4 & 4 & $95 \%$ & I \\
isi & Kemutakhiran pustaka & 4 & 4 & $90 \%$ & I \\
\hline & Rerata kelayakan aplikasi & & & $\mathbf{8 7 \%}$ & I \\
\hline
\end{tabular}

Berdasarkan Tabel 3, diperoleh rerata skor 83\% pada komponen sistematika penyajian, sehingga produk dikategorikan sangat layak dan siap diimplementasikan. Berdasarkan Tabel 4, diperoleh rerata skor $85 \%$ pada komponen bahasa, sehingga produk dikategorikan sangat layak dan siap diimplementasikan. Berdasarkan Tabel 5, diperoleh rerata skor $85 \%$ pada komponen tampilan, sehingga produk dikategorikan sangat layak dan siap diimplementasikan. 
Tabel 3 Data Hasil Uji Ahli Pembelajaran Bahasa Indonesia Komponen Sistematika Penyajian

\begin{tabular}{llcccc}
\hline \multicolumn{1}{c}{ Indikator } & \multicolumn{1}{c}{ Butir Penilaian } & \multicolumn{4}{c}{ Penilaian } \\
\cline { 3 - 6 } Penilaian & \multicolumn{1}{c}{ X } & Xi & HU & TL \\
\hline Teknik & Konsistensi sistematika sajian & 3 & 4 & $80 \%$ & I \\
penyajian & Keruntutan sistematika sajian & 4 & 4 & $85 \%$ & I \\
$\begin{array}{l}\text { Penyajian } \\
\text { dalam } \\
\text { pembelajaran }\end{array}$ & Keruntutan penyajian aplikasi & 4 & 4 & $88 \%$ & I \\
\hline & Keterlibatan peserta didik dalam & 4 & 4 & $85 \%$ & I \\
& pembelajaran menggunakan aplikasi & & & & \\
\hline \multicolumn{2}{c}{ Rerata kelayakan aplikasi } & & & $\mathbf{8 3 \%}$ & I \\
\hline
\end{tabular}

Tabel 4 Data Hasil Uji Ahli Pembelajaran Bahasa Indonesia Komponen Bahasa

\begin{tabular}{|c|c|c|c|c|c|}
\hline \multirow{2}{*}{$\begin{array}{l}\text { Indikator } \\
\text { Penilaian }\end{array}$} & \multirow[b]{2}{*}{ Butir Penilaian } & \multicolumn{4}{|c|}{ Penilaian } \\
\hline & & $\mathbf{X}$ & $\mathbf{X i}$ & HU & TL \\
\hline Kejelasan & Kejelasan kalimat instruksi & 4 & 4 & $90 \%$ & I \\
\hline penggunaan & Kemudahan memahami bahasa & 3 & 4 & $80 \%$ & I \\
\hline bahasa & Ketepatan diksi atau pilihan kata & 4 & 4 & $90 \%$ & I \\
\hline Ketepatan & Ketepatan penggunaan istilah & 4 & 4 & $85 \%$ & $\mathrm{I}$ \\
\hline penggunaan & Kebakuan kata yang dipilih & 3 & 4 & $80 \%$ & I \\
\hline bahasa & Ketepatan tanda baca & 4 & 4 & $95 \%$ & I \\
\hline & Ketepatan diksi dalam manual book & 3 & 4 & $75 \%$ & I \\
\hline & Rerata kelayakan aplikasi & & & $85 \%$ & I \\
\hline
\end{tabular}

Tabel 5 Data Hasil Uji Ahli Pembelajaran Bahasa Indonesia Komponen Tampilan

\begin{tabular}{llcccc}
\hline \multicolumn{1}{c}{ Indikator } & \multicolumn{1}{c}{ Butir Penilaian } & \multicolumn{4}{c}{ Penilaian } \\
\cline { 3 - 6 } Penilaian & \multicolumn{1}{c}{ X } & Xi & HU & TL \\
\hline Desain & Kemenarikan desain bagian home & 3 & 4 & $85 \%$ & I \\
aplikasi & Kontras warna & 3 & 4 & $85 \%$ & I \\
Ilustrasi & Kesesuaian ilustrasi gambar dengan isi & 4 & 4 & $90 \%$ & I \\
gambar & Kemenarikan ilustrasi gambar & 3 & 4 & $75 \%$ & R \\
Tipografi & Kemenarikan pemilihan jenis huruf & 4 & 4 & $90 \%$ & I \\
\hline \multicolumn{2}{c}{ Rerata kelayakan aplikasi } & & & $\mathbf{8 5 \%}$ & I \\
\hline
\end{tabular}

Berdasarkan Tabel 6, diperoleh rerata skor $83,1 \%$ pada komponen isi, sehingga produk dikategorikan sangat layak dan siap diimplementasikan. Berdasarkan Tabel 7, diperoleh rerata skor $80 \%$ pada komponen sistematika penyajian, sehingga produk dikategorikan layak dan siap diimplementasikan. Berdasarkan Tabel 8, diperoleh rerata skor 81,6\% pada komponen bahasa, sehingga produk dapat dikategorikan sangat layak dan siap diimplementasikan. 
Berdasarkan Tabel 9, diperoleh rerata skor $84 \%$ pada komponen tampilan, sehingga produk dikategorikan layak dan siap diimplementasikan.

Tabel 6 Data Hasil Uji Ahli Praktisi Komponen Isi Aplikasi

\begin{tabular}{llcccc}
\hline \multicolumn{1}{c}{ Indikator } & \multicolumn{1}{c}{ Butir Penilaian } & \multicolumn{4}{c}{ Penilaian } \\
\cline { 3 - 6 } \multicolumn{1}{c}{ Penilaian } & \multicolumn{1}{c}{ X } & Xi & HU & TL \\
\hline Kelengkapan & Ketersediaan konten untuk dosen. & 3 & 4 & $80 \%$ & I \\
isi yang & Ketersediaan konten mahasiswa & 3 & 4 & $80 \%$ & I \\
disajikan & Ketersediaan konten untuk pengguna & 3 & 4 & $80 \%$ & I \\
Ketepatan isi & Ketepatan konten pada portal admin & 4 & 4 & $85 \%$ & I \\
& Ketepatan konten pada portal editor & 4 & 4 & $90 \%$ & I \\
& Ketepatan konten portal pengguna & 4 & 4 & $85 \%$ & I \\
Kemutakhiran & Kesesuaian aplikasi dengan & 4 & 4 & $85 \%$ & I \\
isi & perkembangan ilmu dan teknologi & & & & \\
& Kemutakhiran pustaka & 3 & 4 & $80 \%$ & I \\
\hline & $\quad$ Rerata kelayakan aplikasi & & & $\mathbf{8 3 , 1 \%}$ & I \\
\hline
\end{tabular}

Tabel 7 Data Hasil Uji Ahli Praktisi Komponen Sistematika Penyajian

\begin{tabular}{llcccc}
\hline \multicolumn{1}{c}{ Indikator } & \multicolumn{2}{c}{ Butir Penilaian } & \multicolumn{4}{c}{ Penilaian } \\
\cline { 3 - 6 } \multicolumn{1}{c}{ Penilaian } & & X & Xi & HU & TL \\
\hline Kelengkapan & Bagian portal admin di manual book & 3 & 4 & $80 \%$ & I \\
penyajian & Bagian portal editor di manual book & 3 & 4 & $80 \%$ & I \\
& Bagian portal pengguna di manual book & 3 & 4 & $80 \%$ & I \\
Teknik & Keruntutan sistematika sajian laman & 3 & 4 & $80 \%$ & I \\
penyajian & Kemudahan penggunaan laman & 3 & 4 & $80 \%$ & I \\
\hline \multicolumn{2}{c}{ Rerata kelayakan aplikasi } & & & $\mathbf{8 0 \%}$ & I \\
\hline
\end{tabular}

Tabel 8 Data Hasil Uji Ahli Praktisi Komponen Bahasa

\begin{tabular}{|c|c|c|c|c|c|}
\hline \multirow{2}{*}{$\begin{array}{l}\text { Indikator } \\
\text { Penilaian }\end{array}$} & \multirow{2}{*}{ Butir Penilaian } & \multicolumn{4}{|c|}{ Penilaian } \\
\hline & & $\mathbf{X}$ & $\mathbf{X i}$ & HU & TL \\
\hline Kejelasan & Kejelasan kalimat untuk instruksi & 4 & 4 & $85 \%$ & I \\
\hline penggunaan & Kemudahan memahami bahasa & 3 & 4 & $80 \%$ & I \\
\hline bahasa & Ketepatan diksi atau pilihan kata & 4 & 4 & $80 \%$ & I \\
\hline & Rerata kelayakan aplikasi & & & $81,6 \%$ & I \\
\hline
\end{tabular}

Tabel 9 Data Hasil Uji Ahli Praktisi Komponen Tampilan

\begin{tabular}{llcccc}
\hline Indikator & \multicolumn{1}{c}{ Butir Penilaian } & \multicolumn{4}{c}{ Penilaian } \\
\cline { 3 - 6 } Penilaian & \multicolumn{1}{c}{ X } & Xi & HU & TL \\
\hline Desain aplikasi & Kemenarikan desain bagian home & 3 & 4 & $85 \%$ & I \\
& Kontras warna & 3 & 4 & $83 \%$ & I \\
Ilustrasi gambar & Kesesuaian ilustrasi gambar dengan isi & 4 & 4 & $88 \%$ & I \\
& Kemenarikan ilustrasi gambar & 3 & 4 & $75 \%$ & R \\
Tipografi & Kemenarikan pemilihan jenis huruf & 4 & 4 & $89 \%$ & I \\
\hline & Rerata kelayakan aplikasi & & & $\mathbf{8 4 \%}$ & I \\
\hline
\end{tabular}


Setelah produk divalidasi oleh ahli dan praktisi, produk kemudian dilakukan uji coba pada mahasiswa untuk mengetahui kelayakan produk. Dosen sebagai admin memandu mahasiswa mengoperasikan produk dan menjadikan mahasiswa sebagai editor. Dosen memilih naskah yang sudah diunggah oleh pengguna, kemudian mahasiswa menyunting naskah tersebut dan mengunggahnya di portal editor. Setelah mempraktikkan proses penyuntingan dengan suntingpintar.id, mahasiswa diminta mengisi kuesioner kelayakan produk.

Tabel 10 Data Hasil Uji Coba Komponen Isi Aplikasi

\begin{tabular}{llcccc}
\hline \multicolumn{1}{c}{ Indikator } & \multicolumn{1}{c}{ Butir Penilaian } & \multicolumn{4}{c}{ Penilaian } \\
\cline { 3 - 6 } \multicolumn{1}{c}{ Penilaian } & \multicolumn{1}{c}{ X } & Xi & HU & TL \\
\hline Kelengkapan & Ketersediaan konten untuk dosen. & 3 & 4 & $85 \%$ & I \\
isi yang & Ketersediaan konten mahasiswa & 3 & 4 & $90 \%$ & I \\
disajikan & Ketersediaan konten untuk pengguna & 3 & 4 & $92 \%$ & I \\
Ketepatan isi & Ketepatan konten pada portal admin & 4 & 4 & $86 \%$ & I \\
& Ketepatan konten pada portal editor & 4 & 4 & $89 \%$ & I \\
& Ketepatan konten portal pengguna & 4 & 4 & $86 \%$ & I \\
Kemutakhiran \\
isi & Kesesuaian aplikasi dengan & 4 & 4 & $95 \%$ & I \\
& perkembangan ilmu dan teknologi & & & & \\
& Kemutakhiran pustaka & 3 & 4 & $89 \%$ & I \\
\hline
\end{tabular}

Tabel 11 Data Hasil Uji Coba Komponen Sistematika Penyajian

\begin{tabular}{|c|c|c|c|c|c|}
\hline \multirow{2}{*}{$\begin{array}{l}\text { Indikator } \\
\text { Penilaian }\end{array}$} & \multirow{2}{*}{ Butir Penilaian } & \multicolumn{4}{|c|}{ Penilaian } \\
\hline & & $\mathbf{X}$ & $\mathbf{X i}$ & HU & TL \\
\hline Teknik & Konsistensi sistematika sajian & 3 & 4 & $85 \%$ & I \\
\hline penyajian & Keruntutan sistematika sajian & 4 & 4 & $80 \%$ & I \\
\hline Penyajian & Keruntutan penyajian aplikasi & 4 & 4 & $89 \%$ & I \\
\hline $\begin{array}{l}\text { dalam } \\
\text { pembelajaran }\end{array}$ & $\begin{array}{l}\text { Keterlibatan peserta didik dalam } \\
\text { pembelajaran menggunakan aplikasi }\end{array}$ & 4 & 4 & $84 \%$ & I \\
\hline & Rerata kelayakan aplikasi & & & $83 \%$ & $\mathbf{I}$ \\
\hline
\end{tabular}

Tabel 12 Data Hasil Uji Coba Komponen Bahasa

\begin{tabular}{llcccc}
\hline \multicolumn{1}{c}{ Indikator } & \multicolumn{2}{|c}{ Butir Penilaian } & \multicolumn{4}{c}{ Penilaian } \\
\cline { 3 - 6 } Penilaian & X & Xi & HU & TL \\
\hline Kejelasan & Kejelasan kalimat untuk instruksi & 4 & 4 & $87 \%$ & I \\
penggunaan & Kemudahan memahami bahasa & 3 & 4 & $91 \%$ & I \\
bahasa & Ketepatan diksi atau pilihan kata & 4 & 4 & $83 \%$ & I \\
\hline \multicolumn{2}{c}{ Rerata kelayakan aplikasi } & & & $\mathbf{8 7 \%}$ & I \\
\hline
\end{tabular}


Tabel 13 Data Hasil Uji Coba Komponen Tampilan

\begin{tabular}{llcccc}
\hline Indikator & \multicolumn{1}{c}{ Butir Penilaian } & \multicolumn{4}{c}{ Penilaian } \\
\cline { 3 - 6 } Penilaian & \multicolumn{1}{c}{ X } & Xi & HU & TL \\
\hline Desain aplikasi & Kemenarikan desain bagian home & 3 & 4 & $86 \%$ & I \\
& Kontras warna & 3 & 4 & $82 \%$ & I \\
Ilustrasi gambar & Kesesuaian ilustrasi gambar dengan isi & 4 & 4 & $85 \%$ & I \\
& Kemenarikan ilustrasi gambar & 3 & 4 & $80 \%$ & R \\
Tipografi & Kemenarikan pemilihan jenis huruf & 4 & 4 & $87 \%$ & I \\
\hline \multicolumn{2}{c}{ Rerata kelayakan aplikasi } & & & $\mathbf{8 4 \%}$ & I \\
\hline
\end{tabular}

Kemahiran penyuntingan merupakan salah satu kompetensi yang perlu dikuasai oleh lulusan Program Studi Pendidikan Sastra Indonesia yang dijadikan subjek penelitian. Berdasarkan hasil penelitian, diperoleh rerata $85,05 \%$ pada komponen isi, sehingga produk sangat layak dan siap diimplementasikan. Isi merupakan komponen penting dalam kriteria kelayakan agar aplikasi dapat meningkatkan kompetensi penyuntingan. Penyuntingan tidak dapat dilakukan tanpa kajian teori yang tepat. Hal tersebut sejalan dengan teori tentang tingkatan penyuntingan, yaitu penyuntingan sekilas, penyuntingan inti, dan revisi hasil suntingan (Boenisch, 2013).

Berdasarkan hasil penelitian, diperoleh rerata hasil $81,5 \%$ pada komponen sistematika penyajian. Aplikasi dikembangkan dengan sistematika yang runtut, yaitu sajian materi penyuntingan, kemudian media untuk praktik menyunting. Materi penyuntingan perlu dikuasai oleh mahasiswa karena syarat menjadi penyunting, yaitu menguasai ejaan, tata bahasa, memahami kamus, peka bahasa, berpengetahuan luas, teliti, peka terhadap unsur suku ras (agama), luwes, memiliki kemampuan menulis, menguasai bidang tertentu, bahasa asing, serta memahami kode etik (Eneste, 2017).

Berdasarkan hasil penelitian, diperoleh rerata hasil 83,3\% pada komponen bahasa. Aspek kebahasaan perlu diperhatikan oleh penyunting, karena biasanya ada beberapa tipe kesalahan berbahasa yang dilakukan penyunting, misalnya kesalahan ejaan, penulisan kata, dan pengembangan paragraf (Supriyana, 2018). Kaidah ejaan bahasa Indonesia telah dibukukan dalam Pedoman Umum Ejaan Bahasa Indonesia (PUEBI) yang meliputi pemakaian huruf, kata, tanda baca, dan unsur serapan. Pelibatan teknologi dalam pembelajaran sangat penting untuk 
Edukasi: Jurnal Pendidikan, Volume 19 Nomor 2 Tahun 2021

Pengembangan Website "Sunting Pintar" sebagai Inovasi.......

Ariva Luciandika, Kusubakti Andajani, Dewi Ariani, Manavavee Mamah

Halaman 260-274

dilakukan. Teknologi sangat dekat dengan kehidupan sehari-hari masyarakat, sehingga semakin banyak aplikasi dalam jaringan yang dapat digunakan untuk pembelajaran (Maloney \& Liu, 2016). Teknologi informasi juga dapat diimplementasikan dalam pembelajaran humaniora dan bahasa.

Secara umum, edukasi digital memiliki manfaat menumbuhkan ketertarikan mahasiswa, mengembangkan keterampilan berpikir, mengembangkan keterampilan komputer, mendukung kebutuhan pebelajar, dan keterampilan sosial kolaborasi (Crompton et al., 2017). Pembelajaran bahasa memerlukan aplikasi teknologi agar dapat mengikuti perkembangan era, yaitu pembelajaran dengan melibatkan e-learning. E-learning memiliki karakteristik independen terhadap tempat dan waktu (Thohari et al., 2013). Pengertian e-learning dapat mencakup sebuah garis kontinum dari mulai menambahkan komputer dalam proses belajar sampai dengan pembelajaran berbasis website (Herianto, 2013).

Berdasarkan hasil pengembangan produk, dapat dicapai target pembelajaran yaitu mahasiswa mampu mempraktikkan teori penyuntingan yang terdiri atas penyuntingan kebahasaan dan isi. Melalui pengembangan multimedia yang diterapkan dalam laman, mahasiswa memiliki kesempatan berkreasi. Proses kreatif merupakan kegiatan yang dilakukan untuk mengembangkan ide-ide. Ide tersebut biasanya merupakan hasil penelitian dari kelompok tertentu agar dapat bermanfaat untuk masyarakat secara umum. Menurut perspektif sosiokultural, ide biasanya berkembang melalui proses penggabungan antara realita dan konstruksi makna untuk meningkatkan pengetahuan (Ludvigsen et al., 2019).

Laman tidak hanya dapat diakses di laptop atau komputer, namun juga melalui ponsel (mobile learning). Mobile learning berhubungan dengan mobilitas belajar, sehingga pebelajar mampu terlibat dalam kegiatan tanpa harus melakukan di sebuah lokasi fisik tertentu (Wirawan, 2011). Dosen sebagai admin dan mahasiswa sebagai editor memiliki portal akun yang terhubung satu sama lain, sehingga bisa melakukan pembelajaran jarak jauh. Mobile learning merupakan salah satu tren dalam bidang teknologi pendidikan, sehingga diharapkan mampu memfasilitasi kebutuhan belajar semua kalangan (Surahman \& Surjono, 2017). 
Penelitian mengacu pada pembelajaran berbasis entrepreneurship. Pendidikan berbasis wirausaha dapat membentuk dan mengarahkan kemampuan para lulusan untuk bergerak dan mengembangkan kewirausahaan (Ranto, 2016). Entrepreurship dapat dikembangkan jika mahasiswa ditempatkan dalam situasi yang kondusif dan berkesinambungan, karena seorang entrepreneur dapat diajarkan dan diciptakan melalui pendidikan (Ahmad et al., 2013). Pendidikan kewirausahaan bisa dipakai untuk mempersiapkan entrepreneur dalam memahami potensi, termasuk dalam pengembangan usaha start up (Elenurm et al., 2019). Aplikasi "Sunting Pintar" tidak hanya membelajarkan penyuntingan, tetapi juga memberi keuntungan finansial. Penelitian dapat menjadi media bagi mahasiswa untuk mengaplikasikan teori penyuntingan sesuai kebutuhan pengguna.

\section{SIMPULAN}

Penelitian menghasilkan produk berupa aplikasi penyuntingan dengan nama "Sunting Pintar". Aplikasi berupa laman yang bisa digunakan dosen dan mahasiswa dalam pembelajaran penyuntingan. Laman terdiri atas tiga portal, yaitu admin (dosen), editor (mahasiswa), dan pengguna (masyarakat umum). Berdasarkan analisis data, dapat disimpulkan bahwa aplikasi layak dan siap diimplementasikan. Setelah dilakukan uji validasi ahli dan uji coba pada mahasiswa, produk dikategorikan sangat layak dan siap diimplementasikan.

\section{DAFTAR PUSTAKA}

Ahmad, T., Trihastuti, D., \& Runtuk, J. (2013). Analisis Pengaruh Entrepreneurship Education terhadap Perilaku Entrepreneur Mahasiswa. Gema Aktualita, 2(1), 34-43. http://hdl.handle.net/123456789/54.

Arikunto, S. (2011). Prosedur Penelitian: Suatu Pendekatan Praktik. Jakarta: Rineka Cipta.

Boenisch, J. B. (2013). Defining and Describing Editing. Supporting Research Writing: Roles and Challenges in Multilingual Settings. New Delhi: Chandos Publishing. 
Edukasi: Jurnal Pendidikan, Volume 19 Nomor 2 Tahun 2021

Pengembangan Website "Sunting Pintar" sebagai Inovasi.......

Ariva Luciandika, Kusubakti Andajani, Dewi Ariani, Manavavee Mamah

Halaman 260-274

Crompton, H., Lin, Y. C., Burke, D., \& Block, A. (2017). Mobile Digital Games as an Educational Tool in K-12 Schools. Perspectives on Rethinking and Reforming Education, 16(2), 3-17.

Elenurm, T., Viia, K. T., Lassur, S., \& Hansen, K. (2019). Opportunities of the Entrepreneurship Education for Enhancing Cooperation between Start-Up Entrepreneurs and Business Angels. International Journal of Entrepreneurship and Innovation, 38(3), 379-394.

Eneste, P. (2017). Buku Pintar Penyuntingan Naskah. Jakarta: Gramedia.

Herianto, E. (2013). E-Learning, Implementasi Teknologi di Era Belajar: Kajian pada Mata Kuliah Kurikulum PKN di Jurusan PIPS FKIP Universitas Mataram. Jurnal Pendidikan dan Pembelajaran, 20(1), 1-8.

KBBI. (2021). KBBI Daring dalam https://kbbi.kemdikbud.go.id/entri/ penyuntingan. Diakses 19 Juli 2021.

Lamrani, R., Abdelwahed, E. H., Chraibi, S., Qassimi, S., \& Hafidi, M. (2018). Gamification and Serious Games Based Learning for Early Childhood in Rural Areas. New Trends in Model and Data Engineering, 9(1), 79-90.

Ludvigsen, K., Ness, I. J., \& Timmis, S. (2019). Writing on the Wall: How the Use of Technology can Open Dialogical Spaces in Lectures. Thinking Skills and Creativity, 3(4), 1-18.

Maloney, J., \& Liu, J. (2016). Review of Teaching Languages Online. Language Learning \& Technology, 20(3), 37-39.

Margahana, H., \& Triyanto, E. (2019). Membangun Tradisi Entrepreneurship pada Masyarakat. Edunomika, 3(2), 300-309. http://doi.org/10.29040/ jie.v3i02.497.

Miller, T. (2018). Developing Numeracy Skills Using Interactive Technology in A Play-Based Learning Environment. International Journal of STEM Education, 5(39), 1-11.

Nurhidayat, B., Wedi, A., \& Praherdhiono, H. (2020). Pengembangan Multimedia Mobile Learning Berbasis Smartphone Android Materi Huruf Madura untuk SD Negeri 1 Parante Kebupaten Situbondo. JINOTEP: Jurnal Inovasi 
Teknologi Pembelajaran, 6(2), 103-110. http://dx.doi.org/10.17977/ um031v6i22020p103.

Peraturan Pemerintah Republik Indonesia Nomor 4 Tahun 2014 tentang Penyelenggaraan Pendidikan Tinggi dan Pengelolaan Perguruan Tinggi dalam https://lldikti7.ristekdikti.go.id/uploadperaturan/4.\%20PP\%204\% 202014\%20Penyelenggaraan\%20Dikti\%20dan\%20Pengelolaan\%20Dikti.p $d f$. Diakses 9 Agustus 2021.

Ranto, D. W. (2016). Membangun Perilaku Entrepreneur pada Mahasiswa melalui Entrepreneurship Education. JBMA: Jurnal Bisnis Manajemen dan Akuntansi, 3(1), 79-86.

Setiawan, A., Praherdhiono, H., \& Sulthoni. (2019). Penggunaan Game Edukasi Digital sebagai Sarana Pembelajaran Anak Usia Dini. JINOTEP: Jurnal Inovasi Teknologi Pembelajaran, 6(1), 39-44. http://dx.doi.org/10.17977/ um031v6i12019p039.

Supriyana, A. (2018). Penyuntingan Aspek Kebahasaan dalam Naskah Berbahasa Indonesia. Arkhais, 9(2) 133-138.

Surahman, E., \& Surjono, H. D. (2017). Pengembangan Adaptive Mobile Learning pada Mata Pelajaran Biologi SMA sebagai Upaya Mendukung Proses Blended Learning. Jurnal Inovasi Teknologi Pendidikan, 4(1), 26-37. https://doi.org/10.21831/jitp.v4i1.9723.

Thohari, A. N., Satoto, K. I., \& Martono, K. T. (2013). Pembuatan Aplikasi Mobile Learning sebagai Sarana Pembelajaran di Lingkungan Universitas Diponegoro. Jurnal Teknologi dan Sistem Komputer, 1(2), 56-65. https://doi.org/10.14710/jtsiskom.1.2.2013.56-65.

Widiasworo, E. (2017). Inovasi Pembelajaran Berbasis Life Skill dan Entrepreneurship. Yogyakarta: Ar Ruzz Media.

Wirawan, P. W. (2011). Pengembangan Kemampuan E-Learning Berbasis Web ke dalam M-Learning. Jurnal Masyarakat Informatika, 2(4), 21-26. 